\title{
County-Level Spatial Distribution Pattern Construction of Rural Primary and Secondary Schools - A Case Study of the Southeastern Region of Guangxi
}

\author{
Liu Tao, Li Baofeng, and Bi Xiaojia
}

\begin{abstract}
Since the 1980s, China has started to carry out the universal nine-year compulsory education system, a large number of rural primary schools and junior high schools are constructed according to the distribution principles of "every village a primary school" and "every rural township a junior high school". Entering the new century, however, these rural primary and secondary schools are generally facing shortages of enrolling students, due to the "One-Child Policy" and other factors. As a result, China has started to restructure the spatial distribution of rural primary and secondary schools (i.e. school mapping restructure (SMR)). However, due to the impact of administrative divisions, natural, cultural and other factors, the existing methods of adjusting the spatial distribution of rural primary and secondary schools, which involves simply destruction and annexation of individual schools proves to be ineffective, as planning are not systematically carried out. Consequently, there remains significant difficulty for rural students to go to school, due to long travelling distance from home to school, etc. In order to facilitate better planning of the rural school spatial distribution readjustment process, the authors examine rural primary and secondary schools spatial distribution mode at the county level, using the Southeast Region of Guangxi as an example, according to different natural conditions. Relying on an analysis of the status quo administrative structure and school levels, as well as the status quo school spatial distribution, the authors proposed four (4) rural primary and secondary school spatial distribution modes at the county-level, applicable to mountainous regions, plains with low-lying hills and other natural conditions. The authors hope to provide a reference for the renewal and improvement of rural primary and secondary schools distribution at the county level during China's nation-wide school readjustment process.
\end{abstract}

Index Terms-County, rural primary and secondary schools, spatial distribution mode, construction.

\section{INTRODUCTION}

In the 1980s, China launched the universal nine-year compulsory education, according to the layout principles of "every village a primary school", "every rural township a junior high school", China finished the construction of a large number of rural primary and secondary schools, and basically eliminate illiteracy in its rural area. Entering the new century,

Manuscript received March 5, 2016; revised July 13, 2016.

Liu Tao is with the Guigang Urban and Regional Planning Committee, Guigang, P.R. China (e-mail: 243571247@qq.com).

Li Baofeng is with the Huazhong University of Science and Technology, School of Architecture and Urban Planning, Wuhan, P.R. China (e-mail: 535942516@qq.com).

Bi Xiaojia is with Hualan Design and Consulting (Group) Company Limited, No.39 Huadong Road, 24th Floor, Nanning, P.R. China (e-mail: 33911665@qq.com). with the rapid urbanization process, rural population have become increasingly mobile, coupled with the long-term effects of the One-Child Policy, the declining trend of rural school-age population has become increasingly evident. With declining enrollment of students, rural primary and secondary schools are facing crisis [1], [2]. In January 2001, the State Council clearly suggests rational planning and adjustment of school spatial distribution in its "Decision on Education Reform and Development". In March 2001, the Ministry of Education and Ministry of Finance co-issued the "Notice on the Submission of the spatial distribution Restructuring Plan of Primary and Secondary Schools", which officially launched the mass adjustments of rural primary and secondary schools spatial distribution.

This paper takes the densely populated area in the Southeastern Guangxi as an example, through literature research and field survey, it summarizes four school spatial distribution adjustment modes, applicable to areas with different natural topography, in order to simplify planning and administrative implementation as well as to prevent excessive waste of resources. It hopes to serve as a reference of rural primary and secondary schools adjusting their respective spatial distribution.

\section{INTRODUCTION TO THE STUDY AREA}

As used herein, Southeastern Guangxi refers to the area located between $109^{\circ} 11^{\prime} \sim 110^{\circ} 53^{\prime} \mathrm{E}$ and between $20^{\circ} 38^{\prime} \sim 24^{\circ} 02^{\prime} \mathrm{N}$, it is $266 \mathrm{~km}$ long from north to south, and $175 \mathrm{~km}$ wide from east to west. It is a densely populated region. In 2013, the total population of the area of about 11.94 million, the population density is 489 persons / sq km, 2.2 times of Guangxi's average population density of 223 people / sq km, and 3.4 times of China's population density 142 people / sq km.

\section{ANALYSIS OF THE STATUS-QUO SPATIAL DISTRIBUTION OF RURAL PRIMARY AND SECONDARY SCHOOLS}

\section{A. Existence of Obvious Hierarchical Classification of School Spatial Distribution}

Take Guangxi Qintang District rural primary and secondary schools spatial distribution for example, the spatial distribution of rural primary and secondary schools are mostly affected by administrative divisions. It still closely follows the mode developed in the "every village a primary school" and "every rural township a junior high school" era. The junior 
high schools and primary schools in the township follows centralized distribution mode, as they can only be found in townships, only rural primary schools are distributed in villages, obviously following the hierarchy of the administrative system. As can be seen from the surveyed schools, in each of the 10 townships, there is at least one junior high school and central primary schools, however, in villages, only primary schools or teaching points are distributed. Educational resources are concentrated at the township central schools.

\section{B. School Spatial Distribution Structure Diversification}

As seen from the surveyed schools, in the mountainous Zhangmu township of Guangxi's Qintang District, the distribution of schools are affected by the natural environment and the impact of administrative divisions, junior high schools, central primary schools are concentrated around the residence of the township government, and rural primary schools are distributed following tree-like structures along the roads into villages. There is obvious uneven distribution of schools; the further away from the residence of township governments, the fewer schools are distributed. In Shika Township, which is located in a plain with low hills, junior high schools and elementary schools are concentrated at the seat of township government, while the spatial distribution of rural primary schools are distributed relatively evenly along the roads into villages following a network structure.

\section{Largely Different School Service Radius}

There are both mountainous areas and plains with low hills in southeastern Guangxi. As a result, rural primary and secondary schools' spatial distribution show different characteristics. Rural primary and secondary schools on plains are in denser, more even distribution, service radius are smaller, the distance from each settlement point to the nearest elementary school show smaller differences; whereas rural primary and secondary schools in mountainous areas are distributed sparsely, unevenly, with larger school service radius, and longer distance from each settlement point to the nearest elementary school. Such as in Qiaoxu Township and other plain areas, rural elementary school are distributed more evenly and densely, 98 settlement points have nearest schools within a distance of $1 \mathrm{~km}$, accounting for 84.4 percent of all 116 settlements in Qiaoxu Town, 112 settlement point have the nearest schools within a distance of $1.5 \mathrm{~km}$, accounting for 96.5\% percent of all 116 settlements in Qiaoxu Town. For another example, primary schools in Tangwa and other townships in mountainous areas are distributed unevenly and sparsely, 31 settlement points have nearest primary school within the distance of $1 \mathrm{~km}$, accounting for 46.2 percent of all 67 settlement points Watang Township, 59 settlement points have nearest primary school within the distance of $2 \mathrm{~km}$, accounting for 88.1 percent of all 67 settlement points Watang Township. The elementary school with farthest distance to a nearest settlement is Bahe Primary School, with a distance of $2.7 \mathrm{~km}$ to a nearest settlement.

\section{The CONSTRUCTION OF A HIERARCHICAL STRUCTURE FOR SCHOOL SPATIAL DISTRIBUTION ADJUSTMENT}

The spatial distribution adjustment hierarchy of rural primary and secondary schools in counties, we first consider the administrative level, in order to facilitate the implementation and management, secondly we consider school level, in order to determine the size of the school, with a clear scope of service radius.

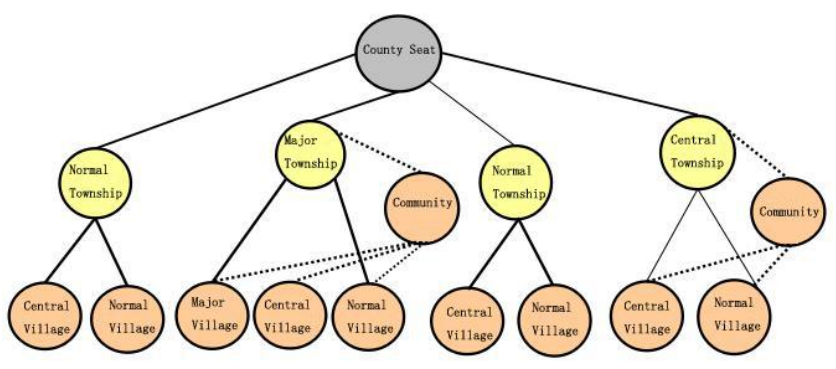

Fig. 1. Modal construction-administrative structure (source: authors).

\section{A. Administrative Structure Construction}

In the spatial distribution adjustment of rural primary and secondary schools, it is unavoidable to consider the problems of uncoordinated and inconsistent administrative divisions and education divisions, among other issues. Stable administrative area boundaries and unstable education area boundaries greatly restricted the effectiveness of administrative divisions adjustment [3]. Under normal circumstances, "County-Township-Village" constitute the three-level administrative divisions of the county administrative system, but in many areas, townships can be divided into central township and general townships, villages can be divided into central villages, and general villages, this five administrative hierarchy is hereby considered in our rural primary school spatial distribution adjustment mode research.

Because of wide development gap between urban and rural area in the county, there is a need to determine the hierarchical structure of the rural primary and secondary school distribution based on the characteristics of administrative divisions. For townships with higher population density, the hierarchy can be divided into five levels "County-Central Township-Normal Township (Community) - Central Village Normal Village"; for townships with smaller population size, he hierarchy can be divided into three levels "County-Township (Central Township)-Village (Community)" (Fig. 1). Meanwhile, the population size is not the same for different levels of administrative divisions (see Table I).

TABLE I: POPULATION DistRIBUTION OF SOUTHEASTERN GUANGXI HIERARCHICAL ADMINISTRATIVE STRUCTURE

\begin{tabular}{llllll}
\hline \hline Administrative Division & County & $\begin{array}{l}\text { County } \\
\text { Seat }\end{array}$ & $\begin{array}{l}\text { Central } \\
\text { Township }\end{array}$ & $\begin{array}{l}\text { Normal } \\
\text { Township }\end{array}$ & Central Village \\
\hline Population (in 10 thousands ) & $50-200$ & $10-100$ & $5-15$ & $3-5$ & $0.2-0.5$ \\
\hline \hline
\end{tabular}




\section{B. School Hierarchy}

The county-level adjustment of the spatial distribution of rural primary and secondary schools targets mainly junior high schools, central primary schools, general primary schools and incomplete primary schools (teaching points).

Junior high school is the initial stage of high school, the transition period for high school, thus belongs to the category of secondary education.

TABLE II: SCHOOLS HIERARCHY CONSTRUCTION AT THE COUNTY LEVEL

\begin{tabular}{|c|c|c|c|c|c|}
\hline Primary and secondary schools & $\begin{array}{l}\text { County } \\
\text { Seat }\end{array}$ & $\begin{array}{c}\text { Central } \\
\text { Township } \\
\end{array}$ & $\begin{array}{c}\text { Normal } \\
\text { Township } \\
\end{array}$ & Central Village & Normal Village \\
\hline Junior high schools & $\bullet$ & $\bullet$ & $\circ$ & $\Delta$ & $\Delta$ \\
\hline Central primary schools & $\bullet$ & $\bullet$ & $\bullet$ & ० & $\Delta$ \\
\hline Complete primary schools & $\bullet$ & $\bullet$ & $\bullet$ & $\bullet$ & $\circ$ \\
\hline $\begin{array}{l}\text { Incomplete primary schools and teaching } \\
\text { points }\end{array}$ & $\Delta$ & $\Delta$ & $\Delta$ & $\Delta$ & $\circ$ \\
\hline Instructions & \multicolumn{5}{|c|}{ •recommended, onon-essential, $\Delta$ not recommended } \\
\hline
\end{tabular}

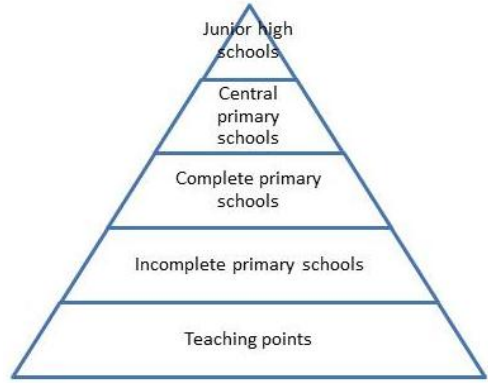

Fig. 2. Modal construction-school hierarchy (source: authors).

Normal primary school is the school in which people accept the first formal school education, is the basic education provided by the state for each school-age children. According to the administrative division, primary schools are divided into central primary schools and complete primary schools; wherein, the central primary schools generally refer to those built in the townships, while general primary school generally refers to those built in the villages outside townships.

Incomplete primary schools (teaching points) are built to serve the needs of local residents, when the scale of classes can not meet the requirements of complete primary schools.

Based on administrative structure and school hierarchy, school distribution adjustment mode construction was given 3 patterns: recommended, non-essential, and not recommended (see Table II).

\section{School Spatial Distribution Modal AdJustment}

County rural primary and secondary schools spatial distribution adjustment model refers to the spatial distribution arrangement forms on which the rural school distribution restructuring process within a county is relying in order to optimize the current distribution of schools. In general, there are two main models of rural primary and secondary schools distribution within the county: one is tree structure mode; the second is network structure mode. Tree structure emphasizes the vertical dimension of rural primary and secondary schools distribution in the county, with little horizontal linkages, most schools in this system are laid out according to administrative system hierarchy, schools are unevenly distributed, with long service radius, students can only attend school in the administrative division $\mathrm{s} /$ he lives in. There remains significant difficulty for students to go to schools far away from their homes, especially in the hilly and mountainous areas. Network structure mode emphasizes the horizontal distribution dimension of a county's rural primary and secondary schools, not restricted by administrative divisions, but only according to a school's size and grade to determine the service radius and the population it serves, schools are distributed evenly, students can enroll in the nearest school, mainly in hilly plains, in order to achieve the comprehensive development of urban and rural education in the county. Therefore, we propose four school spatial distribution adjustment modes, namely, point-axis concentration mode, multi-pole group mode, multi-core network mode, and multi-pole network mode.

\section{A. Point-Axis Concentration Mode}

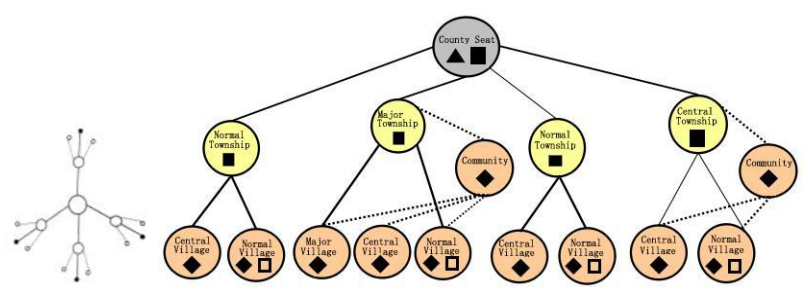

(a) Modal structure (b) School hierarchy construction

Fig. 3. Mode 1: Point-axis concentration mode (source: authors).

Point-axis concentration mode is also known as centralized mode (Fig. 3). This mode, based on the "Growth Pole Theory", highlights the single-core multi-axis tree structure spatial distribution mode [4]. In this distribution mode, rural primary and secondary schools, and junior high schools are principally distributed at the county seats, central primary schools mainly in townships, complete primary schools in village and community centers, incomplete primary schools and teaching points in normal villages, whereby forming the 3-level distribution mode: county - township - village. It is primarily useful in less densely populated hilly and mountainous areas. Core-axis concentration mode is beneficial for taking the advantages of large-scale school education, and centralizing educational resources. It has played a central role in promoting and improving the quality of teaching. But under the impact of administrative divisions, school service radiuses are long, particularly, junior high schools are concentrated at the county seats. The difficulty for students to go to schools far away from their homes, coupled 
with inadequate construction of boarding schools and other facilities, there remains school management difficulties and other outstanding issues.

\section{B. Multi-pole Group Mode}

Multi-pole group mode, also called moderately centralized or moderately decentralized mode (Fig. 4). This mode is based on the "Multi-Core Mode" proposed by Harris, Ullman in 1945. In the county, along with social and economic development and people's growing demand for quality education, rural and urban primary and secondary schools distribution often has more than one (multiple) growth pole (i.e. model high and middle schools). Affected by administrative divisions, hilly and mountainous areas with larger population density, school distribution often follow a tree-like multi-pole structure. Junior high schools and elementary schools are centrally distributed in the center of town and township, complete primary schools in central villages and community centers, in other villages primary schools and teaching points are distributed in accordance with the number of school-age children, whereby forming the multi-pole mode in accordance with the county - township village three-level administrative divisions.

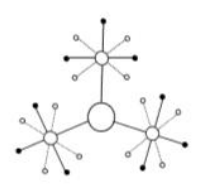

(a) Modal structure

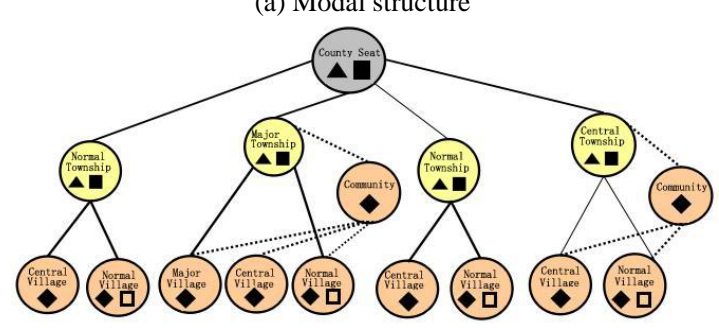

(b) School hierarchy construction

Fig. 4. Mode 2: Multi-pole group distribution mode (source: authors).

The multi-pole group distribution adjustment mode is suited for the reality that rural residences in the county are relatively decentralized. Thus, distributing quality education resources within reasonable service radius appropriate to the size of school will help schools to pursue economies of scale, and to improve teaching quality [5]. But also subject to the impact of administrative divisions, there remain outstanding difficulty and safety problems for students to go to schools far away from their homes, as well as unequal distribution of educational resources and other issues. Meanwhile, with limited investment in education, facility conditions, quality of education and quality of teachers at teaching point are lagging far behind central schools, which is not conducive to the promotion of balanced development and enhance the overall quality of education. Therefore, special attention should be paid to correctly handle the relationship between moderately concentrated and decentralized distribution (Fig. 4).

\section{Multi-core Network Mode}

Multi-core network spatial distribution mode is based on the "Central Place Theory" proposed by German city geographer W. Christaller and the German economist A. Losch respectively in 1933 and 1940. It has been popular in English-speaking countries since the 1950s, following which it was spread to other countries. It is considered one of the most important contributions of human geography of the 20th century, as one of the basic theories of urban agglomeration and urbanization research. Christaller created the "Central Place Theory" under the influence by Thuenen and Weber's Location Theory, therefore, his theory is also based on the "ideal ground", its basic characteristics are that each point has equal opportunity to access a central place, that the relative accessibility of a point and any other point is only proportional to the distance, regardless of orientation, and that there is a unified transport plane. It has central place hierarchical, central goods and services, service radius and other features. Christaller derived his settlement distribution model on the surface of an ideal ground, emphasizing evenly distributed population, particularly suitable for homogeneous distribution of natural conditions, balanced distribution of cores, and plains with good traffic conditions.
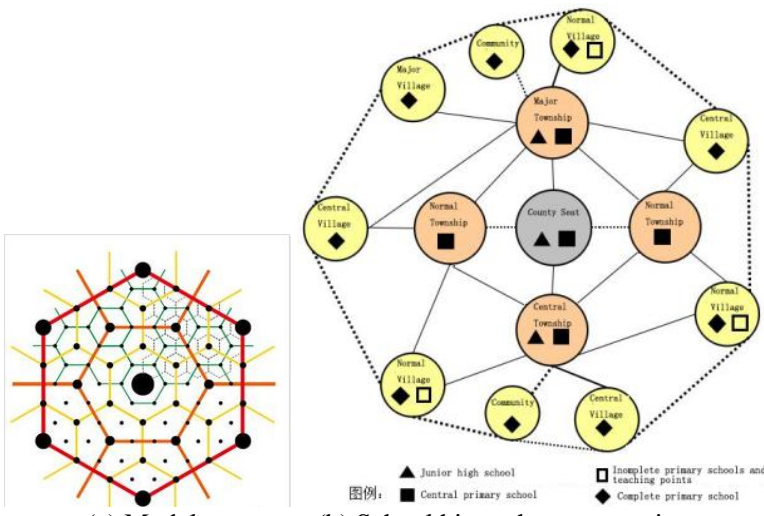

(a) Modal structure (b) School hierarchy construction Fig. 5. Mode 3: Multi-core network mode (source: authors).

In county-level rural primary and secondary schools spatial distribution adjustment in less densely populated plains with low hills, junior high schools are distributed at the county seats, and central townships, central primary schools in central and normal townships, complete primary schools in central villages and communities, other primary schools and teaching points in other villages, reflecting the central role of primary and secondary schools in townships [6]. Schools are distributed without restrictions of their respective administrative divisions, students can choose to go to schools in the same county, realizing the four-level multi-core distribution mode of county seat - central township - normal township - village, schools are relatively evenly distributed, students can go to school at closer distance (Fig. 5).

Multi-core distribution mode is beneficial for the central school to pursue economies of scale, and improve the quality of teaching; it is also conducive to the efficient utilization of educational resources, while building boarding schools in the central area, solving the difficult issues such as school attendance, and promoting balanced development and the overall improvement of education quality.

\section{Multi-pole Network Mode}

The multi-pole network mode is also based on the "multi-core mode" proposed by Harris and Ullman in 1945. 
Together with the cross-network architecture, network architecture as intermediary platform, Harris and Ullman build their own system of network relations and activities based on people themselves, people and people, people and nature, people and society, people and culture, people and the world relations, [7] in order to build a multi-core crossover network structure model that has both a tree structure and a network structure. In the distribution of rural primary and secondary schools, it is mainly reflected in the plain areas with larger population density. In this mode, township is the core for junior high school distribution, junior high schools are distributed in county seats, central and normal townships, central primary schools are distributed in central and normal townships, complete primary schools in central villages and communities, incomplete primary schools and teaching points in normal villages. This mode reflects the central role of school in townships, while building primary schools in central villages and community centers, in order to achieve balanced development of educational resources. School spatial distribution are not restricted by administrative division, students in this county can choose to go to schools in another county, realizing the county - township - village three-level multi-core network spatial distribution mode (Fig. 6).
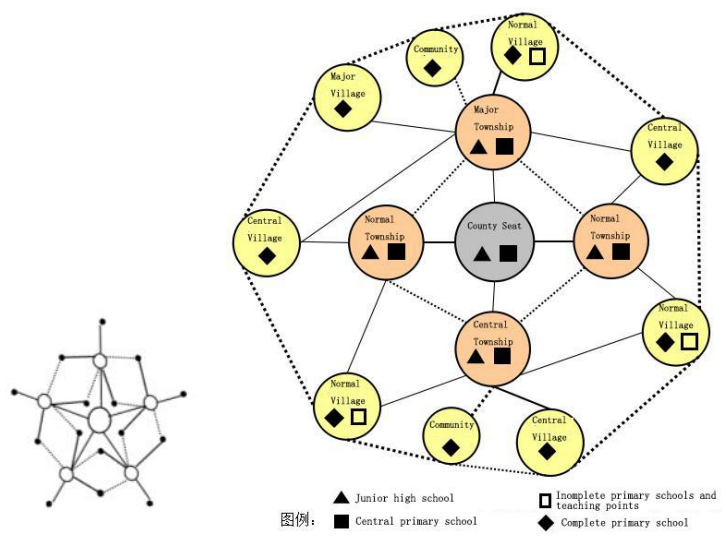

(a) Modal structure (b) School hierarchy construction Fig. 6. Mode 4: Multi-pole network mode (source: authors).

Multi-core network mode is conducive to central schools' pursuit of economies of scale, and to improve teaching quality. Meanwhile, schools and educational resources are distributed evenly and uniformly, high-quality schools are with smaller service radius, which is beneficial for students to go to high-quality schools, and the promotion of balanced education development and enhancement of the overall education quality.

\section{CONCLUSION}

The purpose of researching the rural primary and secondary schools spatial distribution pattern is to change the existing loose, disorderly, inefficient, high input spatial distribution pattern into compact, orderly, efficient and sustainable spatial distribution pattern. Due to the complexity of counties' characteristics, although the value orientation of schools spatial distribution adjustment is clear and simple, but its scope is broad, and its methods multifaceted. Accordingly, the schools spatial distribution adjustment modes should also be varied. This article preliminarily explores primary and secondary school spatial distribution adjustment mode, from the point of view of constructing a hierarchical modal structure system, taking into account the status quo schools spatial distribution, as well as influences from administrative divisions and natural topography. It further clarifies the four modes identified through a comparative analysis of each mode's strengths, weakness and applicable areas. The authors thus hope that this article can provide a useful reference to China's nationwide school consolidation planning process.

\section{REFERENCES}

[1] K. Zhou, D. Liu, Y. Wen et al., "The research of construction plans of rural primary and secondary schools in the Northwest China under the New Situation," Architecture and Culture, vol. 9, pp. 51-53, September 2015.

[2] Q. Guo, "The reasons and solutions for problems in rural school consolidation," Chinese Education and Society, vol. 5, pp. 76-95, May 2013.

[3] H. Wei and G. Zeng, Systems Theory - System of Scientific Philosophy, $1^{\text {st }}$ ed., Beijing, China: Tsinghua University Press, 1995, p. 288.

[4] T. Hawkes and T. Qu, Structuralism and Semiotics, Shanghai, China: Shanghai Yiwen Press, 1987, p. 7.

[5] D. Liu, On the Integration of Educational Resources in Urban Societies, Wuhan, China: Huazhong Normal University Press, 2004, p. 128.

[6] C. Zhou, Analysis of the Economies of Scale of Rural Schools Distribution Restructuring Policy, Shenyang, China: Liaoning Education Research, 2007, p. 11.

[7] J. Chang, Introduction to Network Philosophy — The Reform of Human Existence in the Internet Era, Beijing, China: CCP Central School Press, 2002, p. 15.

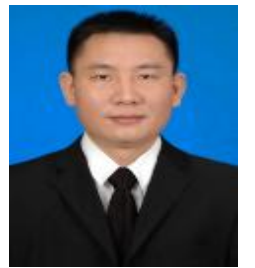

Liu Tao was born in Guangan, Sichuan province, China, in February 1979. He is currently pursuing his doctoral degree in urban and regional planning in Huazhong University of Science and Technology. He holds a bachelor's degree in resources, environment and urban and rural planning management from Xihua University and a master's degree in land use planning from Northwest A\&F University.

$\mathrm{He}$ is currently the deputy head of the Guigang Urban and Regiona Planning Bureau in Guigang City, Guangxi Zhuang Autonomous Region, China. His research interests include land use planning and regional planning.

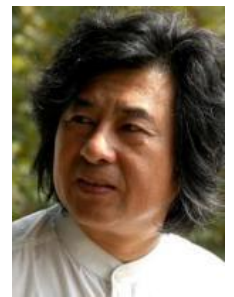

Li Baofeng holds a doctoral degree in urban planning from Tsinghua Univeristy, Beijing, China, a master's degree from Huazhong University of Science and Technology, and a bachelor's degree from Huanan University of Science and Technology.

$\mathrm{He}$ is currently the head of the College of Architecture and Urban Planning of the Huazhong University of Science and Technology in Wuhan City, China. His research interests include green building and energy efficiency. He is a registered architect of the P.R. China.

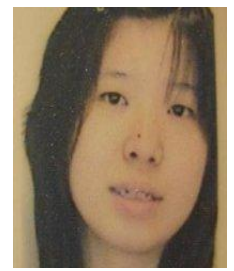

Bi Xiaojia was born in Nanning, Guangxi, China in May 1986. She holds the dual master's degrees in urban and regional planning and international public affairs from the University of Wisconsin-Madison, U.S.A, and a bachelor's degree in land resources management from China Agricultural University in Beijing, China.

She is currently an Urban Planning with Hualan Design and Consulting (Group) Company Limited in Nanning, Guangxi Zhuang Autonomous Region, China. Her research interests are economic planning and international development. 